\title{
Response to water stress in transgenic (p5cs gene) wheat plants (Triticum aestivum $\mathbf{L}$. ) \\ Denise Pavei ${ }^{1}$, Maria Celeste Gonçalves-Vidigal ${ }^{2}$, Adilson Ricken Schuelter ${ }^{3}$, Ivan Schuster ${ }^{3}$, Elisa Serra N. Vieira ${ }^{4}$, Eliane Cristina G. Vendruscolo ${ }^{5}$ and Juliana Parisotto Poletine ${ }^{2 *}$
}

\author{
${ }^{1}$ Bióloga, Mestre, Professora Uniguaçu / Faesi, São Miguel do Iguaçu Pr, Brasil \\ ${ }^{2}$ Departamento de Agronomia, Universidade Estadual de Maringá, Brasil \\ ${ }^{3}$ Cooperativa Central de Pesquisa Agrícola (Coodetec), Cascavel - PR, Brasil \\ ${ }^{4}$ Embrapa Florestas, Colombo - PR, Brasil \\ ${ }^{5}$ Universidade Federal Paraná, Campus Palotina - PR, Brasil
}

*Corresponding author: juliparisotto@ hotmail.com

\begin{abstract}
Transgenic technology in plants has been used to introduce genes that perform as osmoprotection to obtain tolerant to abiotic stresses genotypes. Proline is considered as one of these osmoprotectors. Therefore, $\Delta 1$-pirrolyne-5-carboxylate synthesize (P5CS) enzyme, coded by $p 5 c s$ gene is important and also a limiting factor in its pathway synthesis. This work aimed to evaluate proline accumulation in $p 5 c s$ gene-transformed wheat plants. Experiment was conducted in randomized entirely design with 18 treatments (seven second generation $\left(\mathrm{T}_{2}\right)$ transgenic plants, nine first generation $\left(\mathrm{T}_{1}\right)$ transgenic plants and two checks with and without irrigation) and ten replications. Leaves were collected for conducting analyses of proline content, lipid peroxidation and water relative content every four days. The data were subjected to analyses of variance, using F-test at $1 \%$ and 5\% probability levels and means grouped by Scott and Knott test at $5 \%$ probability level. The results showed that both transgenic and non-transgenic irrigated plants suffered reduction of water accumulation in relation to non-transgenic and plants without irrigation. However, they resisted eight days without water supply and with turgidity. Transgenic plants with constituted promoter (Ubi) and induced stress promoter (aipc) did not present significant differences in relation to proline levels. Lipid peroxidation values did not show any difference between transgenic plants and non-transgenic plants under no irrigation treatments during the evaluation period. The results indicated that transgenic plants produced approximately 1.85 more proline content than normal, demonstrating the $p 5 c s$ gene expression.
\end{abstract}

Keywords: Abiotic stress, cereal crops, gene expression, proline, transformated plants.

Abbreviations: ROS_reactive oxygen species; MDA_malondialdehyde; Ubi_ constitutive promoter of corn Ubiquitine; aipc_induced stress promoter; WRC_water relative content; $T_{0 \_}$transformated plants; $T_{2} 2^{\text {nd }}$ generation of transformed plants.

\section{Introduction}

Wheat (Triticum aestivum L.) is a cereal that widely used in human and animal food around the world. Due to its plasticity for adaptation it can be cultivated in tropical subtropical and regions (Damalgo et al., 2009). In addition, wheat is an important crop in rotation and crop succession in agricultural production units, ensuring economic stream and farmer's sustainability. According to the United Nations Organization for Food and Agriculture (FAO, 2014), there was an increase in world estimate cereals production, around 2,542 million tons, 20 million more than that produced in 2013 agricultural year.

Abiotic stresses, such as soil salinity, water deficit and extreme temperatures are among the main factors that limit plants growth and yield, resulting in high losses to world economy ( $\mathrm{Su}$ and $\mathrm{Wu}, 2004)$. Generally, water deficit modifies the growth and development of cultivated plants, under which the yield is affected differentially by water availability and efficiency by plants (Santos and Carlesso, 1998).

The environmental stress can trigger transcription of some genes that may be widely classified into two groups: those that offer protection and the ones that regulate signal transduction and gene expression associated with other processes (Shinozaki and Yamaguchi-Shinozaki, 2000; Seki et al., 2003; Yamaguchi-Shinozaki and Shinozaki, 2005).

Plants resistance to drought is really complex and its expression depends on the action and interaction of different morphological characters (reduced leaf area, winding leaf, wax content, efficient root system and stability of production); physiological characters (transpiration reduction, high efficiency of water use, stomata closure and osmotic adjustment) and biochemists characters (accumulation of proline, polyamines, diamine, increase in nitrate reductase activity, besides increase in carbohydrate storage). However, the knowledge of genetic mechanisms that condition these characters is limited (Mitra, 2001; Fumis and Pedras, 2002). Obtaining genotypes tolerant to abiotical stresses by classical breeding methods is difficult, mainly due to low heritability and high interaction between genotype $\times$ environments. In addition, selection processes usually occur in non-uniform conditions (Smith et al., 1990). Therefore, plants transformation has demonstrated its capabilities as an excellent option for developing wheat genotypes tolerant to 
drought and more productive (Sahrawat et al., 2003; Jones, 2005).

Increasing tolerance to water deficit stress, by genetic transformation, has been obtained for several species using two main strategies: genes introduction involved in synthesis of osmoprotection molecules or by coding genes of transcription factors (Molinari, 2006). Several mechanisms controlling plant protection against drought, high temperatures and saline soils are known yet. One of them is proline accumulation that is a protein with protective function against the stresses hyper osmotic (Zhu et al., 1998; Hong et al., 2000; Su and $\mathrm{Wu}, 2004)$. Increasing the proline synthesis in plants may aid promote oxidative stress tolerance (Molinari, 2006).

Molecular genetics and genetic engineering has contributed to plants improvement (Pellegrineschi et al., 2002). The studies of important agronomic traits and their behavior in plants subjected to abiotic and biotic stresses allow the assessment of plant responses to these conditions. Such knowledge makes the transgene technology as a strategy obtain information about stress physiology (Vendruscolo, 2005). In wheat specie (Triticum aestivum L.), p5cs gene was introduced into genome through Agrobacterium tumefaciens and transgenic plants subjected to salt stress showed an increase in tolerance (Sawahel and Hassan, 2002). Vendruscolo (2005) obtained twelve lineages of national wheat transformed with $p 5 c s$ gene. The gene induced tolerance to two types of abiotic stress: low temperature and water deficit.

Several studies have demonstrated that genetic manipulation for the higher gene expression and proline production $(p 5 c s)$ increases the production of its osmolyte that acts during stress period, and consequently, results in higher tolerance to it (Kishor et al., 1995; Zhu et al., 1998; Molinari et al., 2004; Vendruscolo, 2005; Molinari, 2006).

Plants genetic transformation has designed to increase tolerance to different types of abiotic stresses based on introduction of osmoregulation genes and transcription factors of genes regulated by abiotic stresses (Shinozaki and Yamaguchi-Shinozaki, 2005). Some strategies use the introduction of one or several genes involved in signaling pathways and regulation or encoding enzymes, resulting in synthesis of compounds that protect cellular structures, such as osmolites and antioxidants (Shinozaki and YamaguchiShinozaki, 2005).

Therefore, this work aimed to evaluate seven wheat lines (Triticum aestivum L.) in $\mathrm{T}_{2}$ generation, as well as to demonstrate proline action mechanism, in relation to the osmotic adjustment and protection of cell membranes.

\section{Results and Discussion}

\section{Genetic analysis of $T_{1}$ plants}

The genetic segregation analyses of p5cs gene in $\mathrm{T}_{1}$ generation were developed based on the expression of bar gene that confers herbicide resistance in all plants transformed by the plasmid, as shown in Table 2 .

Observed segregation in S-6-16, S-84 and S-6-4 transformed families fit the ratio of $3: 1$, indicating the presence of a dominant gene (Table 3). This segregation ratio was not significant at $5 \%$ probability level, a fact that suggests the insertion of a single copy. However, S-6-1 transformed plants, presented $1: 1$ segregation ratio, nonsignificant at $5 \%$ probability level, indicating a differentiated pattern of transgene expression. All transformed plants showed proline expression, demonstrating that the presence of one more copy of gene did not result the silencing effect of transgene in $\mathrm{T}_{2}$ plants.

\section{Evaluation to water stress tolerance}

$\mathrm{T}_{2}$ transgenic plants and control, subjected to water stress, differed significantly ( $1 \%$ probability level) for proline content (Table 4). Proline levels in transgenic plants and control without water stress ( 0 day) were similar and ranged from $1.38 \mu$ moles $\mathrm{g}^{-1}$ of dry matter in transgenic plants to $1.49 \mu$ moles g ${ }^{-1}$ f dry matter in control plants (Fig 1).

Maximum levels of proline were presented by pUbi S2-34 and S-6-1 genotypes, when subjected to eight days of water stress, which accumulated 5.37 and $5.25 \mu$ moles $\mathrm{g}^{-1}$ of dry mass, respectively. The results evidenced a maximum increase of 1.85 times in proline content between transgenic plants and control. Several authors have described proline increase in plants of distinct species, transformed with $p 5 c s$ gene when submitted to water stress, including wheat (Molinari et al., 2004; Vendruscolo, 2005; Molinari, 2006).

Genotypes pUbi although possessing constitutive promoter and continually express $p 5 c s$ gene, did not show high levels of proline in water stress absence. Thus, such observation could be clarified as a result of pUbi also constitutes an induced stress promoter. Christensen and Quail (1996) concluded that mechanical and thermal stresses caused a significant increase in gus gene expression in rice when it used maize ubiquitin promoter.

Water process stress provides stomata closing, reducing the supply of $\mathrm{CO}_{2}$ to chloroplasts and promoting the reduction of photosynthetic activity, a fact that results to the formation of reactive oxygen species (ROS). Consequently, the lipid peroxidation may result in rupture of cell membranes in plants subjected to stress (Hernandez et al., 2000; Mundree et al., 2002; Parvanova et al., 2004). Quantification of lipid peroxidation through indirect methods, such as content of malondialdehyde, is used as a measuring criterion of stress at the cellular level (Parvanova et al., 2004). This experiment showed that transgenic plants had higher MDA content, suggesting a reduced oxidative damage protection.

Regarding to MDA (malondialdehyde) content, the transgenic and control plants subjected to stress, differed significantly (F-test) during the stress only at 0 and 2 times similar to other studied periods (Table 5). During the absence of water stress, MDA values ranged from 0.05 mmoles $\mathrm{g}^{-1}$ of fresh mass in transgenic plants and 0.06 mmoles $\mathrm{g}^{-1}$ of fresh mass in control plants. At $8^{\text {th }}$ day without water supply, the values were 0.07 mmoles $\mathrm{g}^{-1}$ of fresh mass in control plants. Although values are similar, plants subjected to water stress showed higher levels of MDA with difference statistic in comparison to irrigated control plants (Fig 2). The eighth day of water stress showed 0.062 mmmoles $^{-1}$ of fresh mass for S-6-4 plants as the most inferior MDA value obtained for transgenic plants, whereas the highest value was 0.093 
Table 1. Transformed plants $\left(\mathrm{T}_{2}\right)$ and its respective families.

\begin{tabular}{ll}
\hline Transformed plants & Families \\
\hline S-84 & $(134,101,48,18,15)$ \\
S-88 & $(136,124,90,72,61)$ \\
S-6-4 & $(5,4,3,2,1)$ \\
pUbi S2 & $(34,32,30,26,13,12,11,10,8,6)$ \\
S-6-14 & $(109,105,78,53,24)$ \\
S-6-16 & $(135,91,75,54,9)$ \\
S-6-1 & $(3,2,1)$ \\
\hline
\end{tabular}
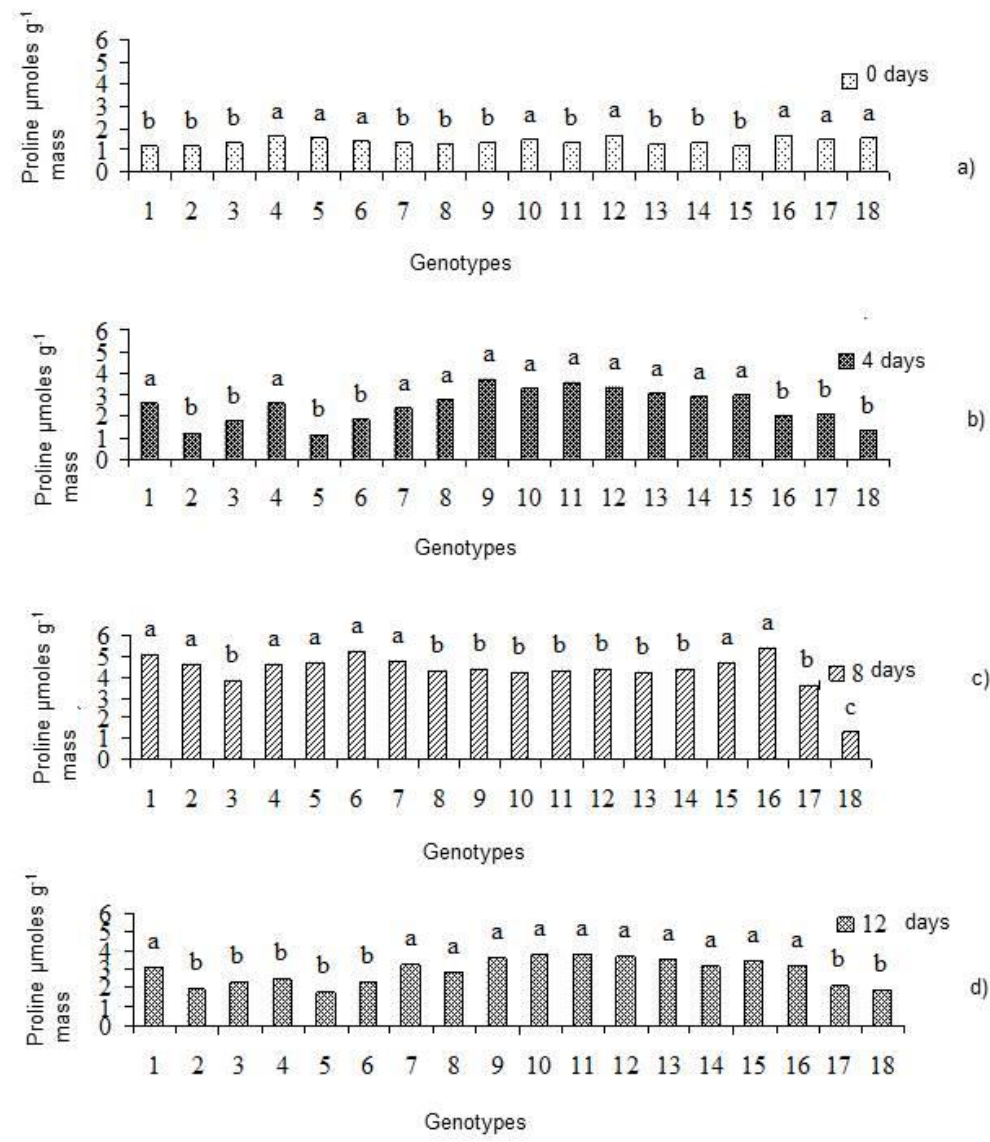

Fig 1. Proline content ( $\mu$ moles $g^{-1}$ of dry matter) in plants subjected to water stress at 0 (a), 4 (b) and 8 (c) days and after irrigation (d). Events from 1 to $16=$ transformed plants, $(1$ to 6 : promoter water stress; 7 to 16 : constitutive promoter). Event $17=$ control under water stress. Event 18 = irrigated control. Means followed by the same letter do not differ significantly by Scott Knott test, at $5 \%$ probability level.

mmmoles $\mathrm{g}^{-1}$ of fresh mass for S-6-14 plants. On the other hand, control plants submitted to stress showed MDA value around $0.069 \mathrm{mmmoles}^{-1}$ of fresh mass. The control plants presented 0.052 mmmoles $\mathrm{g}^{-1}$ of fresh mass when irrigated, demonstrating a greater integrity and maintenance of physiological processes, an expected result since these ones have not suffered stress. This experiment evidenced that transgenic plants presented higher MDA content, suggesting a reducing protection to oxidative damage. These results disagreed from other studies that showed highest proline content and inferior MDA content by an imposition of water restriction (Vendruscolo, 2005).

This fact indicates that despite of high content in proline accumulation among transgenic plants, there was no efficient mechanism for cell membrane protection against oxidative stress.
Proline content in transgenic plants with constitutive promoter (Ubi) and induced stress promoter (aipc) did not present any significant difference. Results indicated that MDA values did not differ between transgenic and no transgenic plants under water stress during evaluation period. Analysis of water relative content (WRC) revealed significant differences by $\mathrm{F}$ test at $1 \%$ probability level among control plants and events (Table 6). Considering these results, it is observed that likewise the transgenic plants, control ones could resist eight days without water supply, showing turgidity. In the absence of water stress, transgenic and control plants showed values ranging from $85.02 \%$ to 89.39 $\%$, respectively, with no significant difference (Fig 3). Throughout the water stress process, in the period of four and eight days, both transgenic and control plants, subjected 
Table 2. Identification of evaluated treatments.

\begin{tabular}{ll}
\hline Identification of evaluated treatments & Transformed plants \\
\hline 1 & S-88 \\
2 & S-16 \\
3 & S-84 \\
4 & S-6-14 \\
5 & S-6-4 \\
6 & S-6-1 \\
7 & pUbi S2-6 \\
8 & pUbi S2-8 \\
9 & pUbi S2-10 \\
10 & pUbi S2-11 \\
11 & pUbi S2-12 \\
12 & pUbi S2-13 \\
13 & pUbi S2-26 \\
14 & pUbi S2-30 \\
15 & pUbi S2-32 \\
16 & pUbi S2-34 \\
17 & Control, without irrigation \\
18 & Control, with irrigation \\
\hline
\end{tabular}
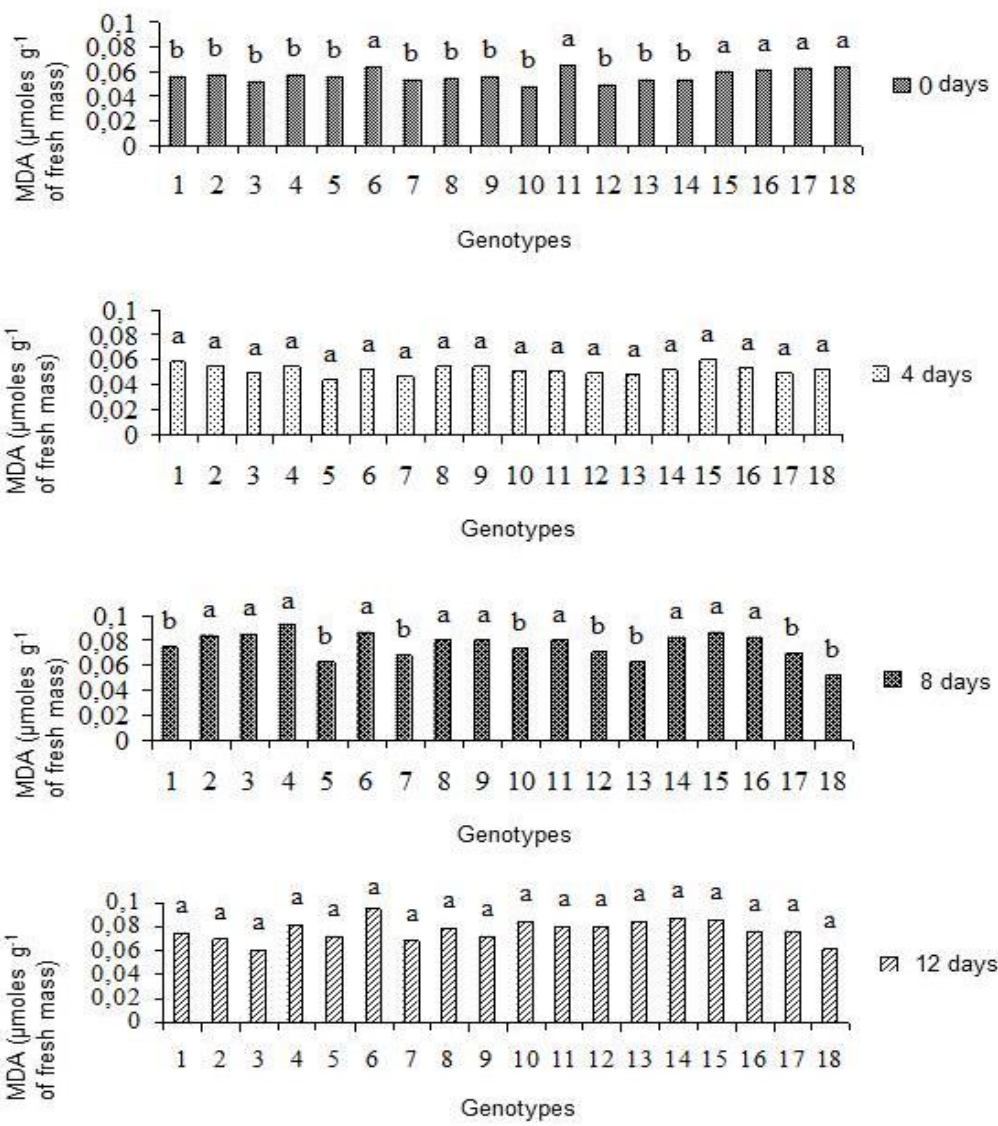

Fig 2. Levels of membrane peroxidation (MDA in mmoles $\mathrm{g}^{-1}$ of fresh mass) obtained in plants subjected to water stress at $0,4,8$ days and after irrigation. Events from 1 to $16=$ transformed plants ( 1 to 6 : induced stress promoter; 7 to 16 : constitutive promoter). Event $17=$ control under water stress. Event $18=$ irrigated control. Means followed by the same letter do not differ significantly by Scott Knott test at 5\% probability level.

to water stress demonstrated a reduction in water relative content (WRC). Transgenic plants showed values that ranged from $37.14 \%$ (pUbi S2-32) to $65.24 \%$ (S-6-4). On the other hand, control stressed plants showed $57.47 \%$ of WRC, whereas control irrigated plants presented $84.74 \%$ (Fig 3).

\section{Materials and Methods}

\section{Plant material and cultivation conditions}

Transgenic wheat plants containing $p 5 c s$ gene used in this experiment were obtained from Universidade Federal do Paraná, Brasil. 
Table 3. Segregation ratio of events obtained by transformation with $p 5 c s$ gene in $\mathrm{T}_{1}$ generation with induced stress promoter.

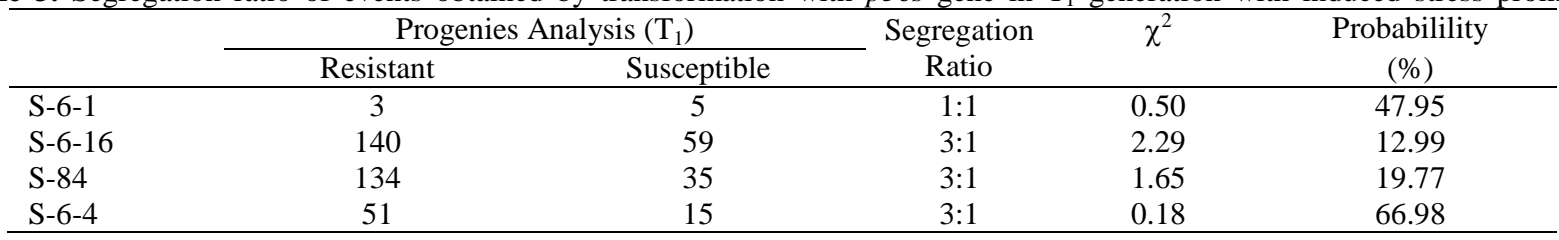
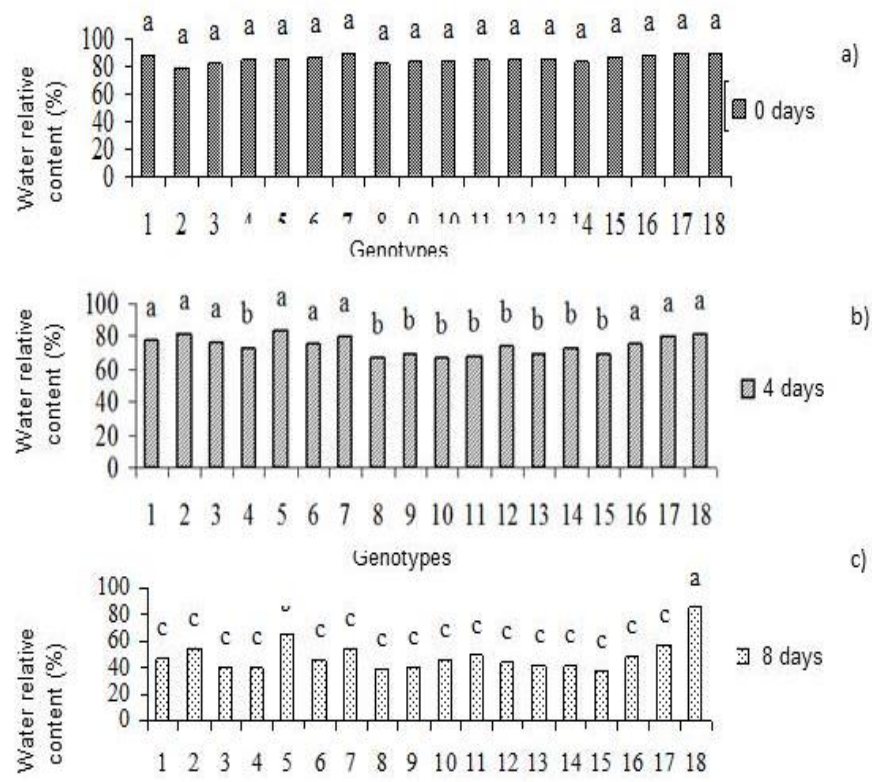

a)

Genotypes

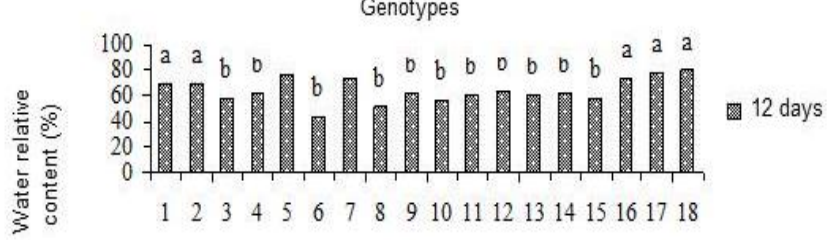

d)

Genotypes

Fig 3. Levels of water relative content (\%) obtained in plants submitted to water stress at 0 (a), 4 (b) and 8 (c) days and after irrigation (d). Events from 1 to $16=$ transformed plants ( 1 to 6 : induced stress promoter; 7 to 16 : constitutive promoter). Event $17=$ control under water stress. Event $18=$ irrigated control. Means followed by the same letter do not differ significantly by Scott Knott test at $5 \%$ probability level.

In 2005 agricultural year, 12 transformed plants $\left(\mathrm{T}_{0}\right)$ with p5cs gene tolerant to water stress were obtained and lately multiplied. The present study evaluated seven of these plants transformed in $\mathrm{T}_{2}$ ( $2^{\text {nd }}$ generation of transformed plants), as shown in Table 1. The experiments were performed at Laboratory of Biotechnology of Cooperativa Central de Pesquisa Agrícola in 2006 year. The pUbiS2 plants were obtained by co-transformation between pUbip 5 csf $129 a$ plasmids (Zhang et al., 1995), presenting code sequence of p5cs gene positioned below the constitutive promoter of maize Ubiquity $(U b i)$. Vigna aconitifolia cDNA, showing replacement of phenylalanine by alanine at 129 position and, with TNOS sequence (nopaline synthase terminator sequence of Agrobacterium tumefasciens, and pAHC2O plasmid containing bar gene), was used as a check mark under the control of constitutive promoter of maize Ubiquity (Ubi) (Christensen and Quail, 1996). Remaining plants were transformed with pJS107 plasmid, containing the compound transgene by promoter stress induced aipc and code sequence p5cs gene from Vigna aconitifolia L. (Hu et al., 1992). The aipc promoter is $\mathrm{ABA}$ induced, possessing an $\mathrm{ABA}$ element responsive with $49 \mathrm{bp}$ from hva 22 barley gene (Shen and Ho, 1995), minimum promoter of acting actl with $100 \mathrm{bp}(\mathrm{Su}$ et al., 1998) and an intron of hva 22 (Shen and Ho, 1995). The bar gene of glifosinato ammonium tolerance was used in transgene as a selection marker under the promoter control CaMV 35 (Hu et al., 1992).

\section{Evaluation of $T_{1}$ plants resistant to Glufosinate ammonium}

$\mathrm{T}_{1}$ genotypes were multiplied and their progenies were evaluated for resistance to ammonium Glufosinate herbicide. Seeds were sown in a tray with sterile soil under greenhouse conditions. After 15 days of initial seed germination, seedlings were sprayed with aqueous solution $1 \%(\mathrm{v} / \mathrm{v})$ of the same herbicide. After a week, the evaluation of seedlings susceptibility and resistance was conducted. The seedlings with healthy growth and green leaves, even with herbicide application considered resistant. Data were analyzed using 
Table 4. Values and significance of medium squares (MS) in $T_{2}$ wheat transgenic plants and control based on proline content, subjected to 0,4 , and 8 days of water stress and after irrigation initiation at $12^{\text {nd }}$ day.

\begin{tabular}{|c|c|c|c|c|c|c|c|c|}
\hline \multirow{3}{*}{ Variation Sources } & \multicolumn{6}{|c|}{ Periods of induced water stress } & \multicolumn{2}{|c|}{ After irrigation } \\
\hline & 0 day & & $4^{\text {th }}$ day & & $8^{\text {th }}$ day & & $12^{\text {nd }}$ day & \\
\hline & FD & MS & FD & MS & FD & MS & FD & MS \\
\hline Replications & 9 & 0.04 & 9 & 0.69 & 9 & 0.82 & 9 & 0.97 \\
\hline Genotypes & 17 & $0.26 * *$ & 17 & $5.84 * *$ & 17 & $4.92 * *$ & 17 & $3.07 * *$ \\
\hline Error & 144 & 0.06 & 142 & 1.11 & 124 & 0.47 & 89 & 0.66 \\
\hline Total & 170 & & 168 & & 150 & & & 115 \\
\hline Mean & - & 1.39 & - & 2.46 & - & 4.24 & - & 2.59 \\
\hline
\end{tabular}

Table 5. Values and significance of medium squares (MS) for lipid peroxidation (MDA) in $T_{2}$ wheat transgenic plants and control, subjected to 0,4 , and 8 days of water stress and after irrigation initiation at $12^{\text {nd }}$ day.

\begin{tabular}{|c|c|c|c|c|c|c|c|c|}
\hline \multirow{3}{*}{$\begin{array}{l}\text { Variation } \\
\text { Sources }\end{array}$} & \multicolumn{6}{|c|}{ Periods of induced water stress } & \multirow{2}{*}{\multicolumn{2}{|c|}{$\begin{array}{l}\text { After irrigation } \\
12^{\text {nd }} \text { day }\end{array}$}} \\
\hline & \multicolumn{2}{|l|}{0 day } & \multicolumn{2}{|c|}{$4^{\text {th }}$ day } & \multicolumn{2}{|c|}{$8^{\text {th }}$ day } & & \\
\hline & FD & MS & FD & MS & FD & MS & FD & MS \\
\hline Blocks & 9 & 0.000007 & 9 & 0.00009 & 9 & 0.00026 & 9 & 0.0021 \\
\hline Genotypes & 17 & $0.00027 * *$ & 17 & $0.00015^{\mathrm{ns}}$ & 17 & $0.00088 * *$ & 17 & $0.0073^{\mathrm{ns}}$ \\
\hline Error & 149 & 0.00007 & 149 & 0.00012 & 148 & 0.0003 & 237 & 0.0005 \\
\hline Total & 175 & & 175 & & 174 & & 254 & \\
\hline Mean & - & 0.056 & - & 0.051 & - & 0.077 & - & 0.078 \\
\hline
\end{tabular}

VS $=$ Variation Sources; FD = Freedom degrees; MS $=$ Medium Square; ${ }^{* *}$ significant at $1 \%$ probability level, by $\mathrm{F}$ test; ${ }^{\mathrm{ns}}=$ no significant.

Table 6. Values and significance of medium squares for water relative content (WRC) in $T_{2}$ wheat transgenic plants and control, submitted to 0,4 and 8 days of water stress and after the beginning of irrigations at $12^{\text {nd }}$ day.

\begin{tabular}{|c|c|c|c|c|c|c|c|c|}
\hline \multirow{2}{*}{$\begin{array}{l}\text { Variation } \\
\text { Sources }\end{array}$} & \multicolumn{4}{|c|}{ Periods of induced water stress } & \multicolumn{2}{|c|}{$8^{\text {th }}$ day } & \multicolumn{2}{|c|}{$\begin{array}{c}\text { After irrigation } \\
12^{\text {nd }} \text { day }\end{array}$} \\
\hline & FD & MS & FD & MS & FD & MS & FD & MS \\
\hline Blocks & 9 & 53.97 & 9 & 133.42 & 9 & 257.28 & 9 & 111.72 \\
\hline Genotypes & 17 & $68.02^{\mathrm{ns}}$ & 17 & $280.15^{*}$ & 17 & $1039.75^{* *}$ & 17 & $687.28 * *$ \\
\hline Error & 145 & 48.27 & 149 & 135.91 & 149 & 201.66 & 112 & 218.07 \\
\hline Total & 171 & & 175 & & 175 & & & 138 \\
\hline Mean & - & 85.33 & - & 74.57 & - & 47.71 & - & 64.24 \\
\hline
\end{tabular}

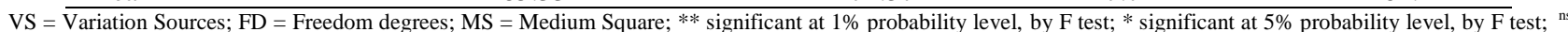
$=$ no significant

Chi-square $\left(\chi^{2}\right)$, to calculate ratio probability according to expected by Mendelian segregation patterns, at $5 \%$ probability level.

\section{Obtaining $T_{2}$ plants}

$\mathrm{T}_{2}$ seeds were sown in pots containing substrate $(50 \%$ soil: $30 \%$ organic fertilizer: $20 \%$ sand), maintained under greenhouse conditions with temperatures ranging from $25^{\circ} \mathrm{C}$ to $26^{\circ} \mathrm{C}$. Experiment was conducted in randomized entirely design with 18 treatments, each one possessing 12 pots with three plants per pot.

After 15 days of initial seed germination, herbicide application (solution of $25 \mathrm{~mL}^{-1}$ ) was performed for selecting transformed seedlings with Glufosinate ammonium tolerance. The pUbi S2 plants, since were obtained by cotransformation, did not receive selective test application and; therefore, all plants were considered in the evaluation. Thinning process was conducted in treatments that showed all resistant plants to herbicides, resting only one plant per pot.

Among the events, in which not all families were tolerant to herbicide or showed heterozygosity, 25 plants were selected for each event. Under the same growing conditions, 24 control plants, genetically untransformed, belonging to CD 200126 lines were sown. From 24 plants control, 17 plants were subjected to water stress and the other ones were irrigated during the same period. Table 2 presents evaluated transgenic plants.

\section{Water stress application}

Plants were subjected to water deficit when reached booting phase, approximately 58-65 days after germination (Zadocks et al., 1974). Control and transformed plants were subjected to a period of eight days with water stress, returning to irrigation at ninth day. Pots were arranged at greenhouse, in similar positions in relation to solar radiation incidence. Leaves collected in order to conducted analyses of relative water content (RWC), proline and MDA (Malondialdehyde) were developed every four days.

\section{Physiological characteristics evaluated}

Physiological analyses were performed at Biotechnology Laboratory belonging to Coodetec in Cascavel County, Paraná State. Leaves collection was standardized according to the methodology proposed by Vendruscolo (2005). To conduct proline analysis the flag leaves were always collected. For MDA evaluation the second leaf below the flag leaf was used. For relative water content (RWC) the third leaf below the flag leaf was analyzed. Collections were conducted during morning period at early hours of the day. Material used for proline and MDA analysis after sampling, was immediately weighted and stored at a temperature of $-80^{\circ} \mathrm{C}$. Leaves for analysis of relative water content were weighted and immediately dried. 


\section{Relative water content (RWC)}

Evaluations about relative water content (RWC) were conducted according to the methodology proposed by Saíram et al. (1998), using the third fully expanded leaf of each plant. After collecting, leaves were stored in plastic bags and sent to the laboratory for determining leaves fresh mass.

Turgid mass was obtained after leaves imbibition for 16-18 hours in distilled water under environmental temperature and in glass packaging previously washed and autoclaved. After this period, leaves were quickly dried with paper towels and weighted.

Dry mass was obtained after material drying in forced air chamber at $70^{\circ} \mathrm{C}$ for 72 hours. The WRC was calculated according to Schonfeld et al. (1988) equation, as follow:

$$
\text { WRC }(\%)=(\text { FM }-\mathrm{DM}) /(\mathrm{TM}-\mathrm{DM}) \times 100
$$

Where;

$\mathrm{FM}=$ Fresh Mass

$\mathrm{DM}=$ Dry Mass

$\mathrm{TM}=$ Turgid Mass

The water relative content (WRC) was determined to evaluate the maximum period of turgidity maintenance of cells in transformed and untransformed plants.

\section{Lipids peroxidation level}

Lipids peroxidation level was measured in terms of malondialdehyde contents (MDA) using thiobarbituric acid reaction (Sairam et al., 1998). Therefore, for this analysis the second leave of each plant was used, weighing about $0.25 \mathrm{~g}$ of leaf tissue that was stored in aluminum foil at a temperature of $-80^{\circ} \mathrm{C}$ during collections periods.

In order to determine MDA content, samples were homogenized in $5 \mathrm{~mL}$ of $0.1 \%$ trichloroacetic acid (w/v) and centrifuged at $14,000 \mathrm{rpm}$ for 5 minutes at environment temperature. Subsequently, $2 \mathrm{~mL}$ of supernatant were removed from each sample, $4 \mathrm{~mL}$ of thiobarbituric acid solution $(0.5 \%$ in $20 \%(\mathrm{w} / \mathrm{v})$ of trichloroacetic acid) was added. Then, this mix was maintained in bain-marie at $100^{\circ}$ $\mathrm{C}$ for 30 minutes. Samples were centrifuged again for 5 minutes at 14,000 rpm for particles sedimentation of plant tissue (Saíram et al., 1998).

Absorbances at 532 and $600 \mathrm{~nm}$ wavelengths of each sample were read in spectrophotometer. Reading at $600 \mathrm{~nm}$ was used for not specific turgidity correction. The MDA content was calculated by the formula shown below, where the $155 \mathrm{mmol}^{-1} \mathrm{~cm}^{-1}$ values corresponds to extinction coefficient.

$$
\mathrm{MDA}=\left(\mathrm{A}_{532}-\mathrm{A}_{600}\right) / 0.155
$$

\section{Proline quantification}

Proline quantification was performed using the flag leaf of each plant (Bates et al., 1973). Aapproximately, 0.025g of leaf material was weighed for proline analysis in two repetitions. Another sample of the same mass was weighted to determine dry mass. Later, samples were packed in aluminum foil and stored in freezer at $-80^{\circ} \mathrm{C}$, during collection period. Proline levels in plants tissues were determined by methodology proposed for Bates et al. (1973), with modifications. A $0.025 \mathrm{~g}$ of plant tissue was macerated in $5 \mathrm{~mL}$ of $10 \%$ sulfosalicylic acid solution. Solution was transferred to falcon tubes of $15 \mathrm{~mL}$ and centrifuged at 7500 rpm for 5 minutes. Then, $2 \mathrm{~mL}$ of supernatant was transferred to new tubes and $2 \mathrm{~mL}$ of ninhidrin acid and $2 \mathrm{~mL}$ of glacial acetic acid were added. Tubes were kept in bain-marie at $100^{\circ} \mathrm{C}$ for 60 minutes, with final reaction conducted on ice bath. After thermal shock, $4 \mathrm{~mL}$ of toluene was added and solution was homogenized for about 20 seconds in Vortex for complete proline extraction. Absorbance at $520 \mathrm{~nm}$, of each sample of its material, was determined on spectrophotometer, using toluene as white. Proline concentration was determined from a standard curve and calculated on the basis of samples dry weight. Materials designed for obtaining dry mass were placed in forced air chamber at $70^{\circ} \mathrm{C}$ and dry mass value obtained after 24 hours (Bates et al., 1973).

\section{Statistical analysis}

The analysis of variance was performed using $\mathrm{F}$ test at $1 \%$ and 5\% probability level. Subsequently, means of treatments were compared by Scott and Knott test (1974) at 5\% probability level. The analyses were developed using Genes computer program (Cruz, 2013).

\section{Conclusion}

Transgenic plants produced approximately 1.85 times more performance than non-transgenic plants, when subjected to water stress, demonstrating the expression of $p 5 c s$ gene. Proline content in transgenic plants with constitutive promoter (Ubi) and stress induced promoter (aipc) did not show significant differences and MDA values did not differ between transgenic plants and no transgenic plants with water stress, during the evaluation period.

\section{Acknowledgements}

The authors Denise Pavei and Maria C. Gonçalves Vidigal were sponsored by Capes-Brazil.

\section{References}

Bates LS, Waldren RP, Teare ID (1973) Rapid determination of free proline for water studies. Plant Soil. 39:205-208.

Christensen AH, Quail PH (1996) Ubiquitin promoter-based vectors for high-level expression of selectable and/or screenable marker genes in monocotyledonous plants. Transgenic Res. 5:213-218.

Cruz CD (2013) Genes a software package for analysis in experimental statistics and quantitative genetics. Act Sci Agr. 35:271-276.

Dalmago GA, Pasinato A, Cunha GR, Pires JLF (2009) Cultivo de trigo. In: Embrapa Trigo (ed) Proceedings of wheat crop, Passo Fundo, 2009.

FAO (2014) Faostat database gateway. Available at http://faostat.fao.org. Access in 19, January.

Fumis TF, Pedras JF (2002) Proline, diamine and polyamines accumulation in wheat cultivars submitted to water deficits. Pesqui Agropec Bras. 37:449-453.

Hernandez JA, Jiménez A, Mullineaux PM, Sevilia F (2000) Tolerance of pea (Pisum sativum L.) to long-term salt stress is associated to induction of antioxidant defenses. Plant Cell Environ. 23:853-862.

Hong Z, Lakkineni K, Zhang Z, Verma DPS (2000) Removal of the feedback inhibition of $\Delta^{1}$-pyrroline-5-carboxylate synthetase results in increase proline accumulation and protection of plants from osmotic stress. Plant Physiol. 122:1129-1136. 
Hu CA, Delauney AJ, Verma DPS (1992) A bifunctional enzyme $\Delta^{1}$-pyrroline-5-carboxylate synthetase catalyses the first two steps of proline biosynthesis in plants. Proc Natl Acad Sci USA. 89: 9354-9358.

Jones HD (2005) Wheat transformation: current technology and applications to grain development and composition. $\mathbf{J}$ Cereal Sci. 41:137-147.

Kishor PBK, Hong Z, Miao GH, Hu CA, Verma DPS (1995) Over expression of $\Delta^{1}$-pyrroline-5-carboxylate synthetase increases proline production and helps maintain osmotic potential in transgenic plants during stress. Plant Physiol. 108:1387-1394.

Mitra J (2001) Genetics and genetic improvement of drought resistance in crop plants. Curr Sci. 80:758-763.

Molinari HBC (2006) Expressão estresse-induzida do gene p5cs em plantas transgênicas de cana-de-açúcar submetidas ao déficit hídrico. Londrina: Universidade Estadual de Londrina, Thesis (Doctor of Science).

Molinari HBC, Marur CJ, Bespalhok Filho, JC, Kobayashi AK, Pileggi M, Melkjunior RP, Peartree LFP, Vieira LCG (2004) Osmotic adjustment in transgenic citrus rootstock Carrizo citrange (Citrus sinensis Osb. $\mathrm{x}$ Poncirus trifoliate L. Raf) overproducing proline. Plant Sci. 167:1375-1381.

Mundree SG, Baker B, Mowla S, Peters S, Marais S, Clare VW, Govender K, Maredza A, Muyanga S, Farrant JM, Thomson A (2002) Physiological and molecular insights into drought tolerance. Afr J Biotechnol. 1:28-38.

Parvanova D, Ivanov S, Konstantinova T, Karanov E, Atanassov A, Tsvetkov T, Alexeeva Y, Djilianov D (2004) Transgenic tobacco plants accumulating osmolytes show reduced oxidative damage under freezing stress. Plant Physiol Bioch. 42:57-63.

Pellegrineschi A, Ribaut JM, Trethowan R, YamaguchiShinozaqui K, Hoisington A (2002) Progress in the genetic engineering of wheat for water-limited conditions. Jir Work Rep. 42:55-60.

Sahrawat AK, Becker D, Lutticke S, Lorz H. (2003) Genetic improvement of wheat via alien gene transfer, an assessment. Plant Sci. 165:1147-1168.

Saíram RK, Desmukh PS, Saxena DC (1998) Role of antioxidant systems in wheat genotypes tolerant to water stress. Biol Plantarum. 41:387-394.

Santos RF, Carlesso R (1998) Water deficit and morphologic and physiologic behavior of the plants. Rev Bras Eng Agr Amb. 2:287-294.

Schonfeld MA, Johnson RC, Carver BF, Mornhinweg DW (1998) Water relations in winter wheat as drought resistance indicator. Crop Sci. 28: 526-531.

Scott A, Knott M (1974) Cluster-analysis method for grouping means in analysis of variance. Biometrics. 30:507-512

Seki M, Kamei A, Yamaguchi-Shinozaki K, Shinazaki K (2003) Molecular responses to drought, salinity and frost: common and different paths for plant protection. Curr Opin Biotech. 14:194-199.
Shen Q, Ho TH (1995) Functional dissection of an absicic acid (ABA) - inducible gene reveals two independent ABA-responsive complexes each is containing a G-box and a novel cis-acting element. Plant Cell. 7:295-307.

Shinozaki K, Yamaguchi-Shinozaki K (2005) Organization of cis-acting regulatory elements in osmotic and coldstress-responsive promoters. Trends Plant Sci. 10:88-94.

Shinozaki K, Yamaguchi-Shinozaki K (2000) Molecular responses to dehydration and low temperature: differences and cross talk between two stress signaling pathways. Curr Opin Plant Biol. 3:217-223.

Smith OS, Smith JSC, Bowen SL, Tenborg RA, Wall SJ (1990) Similarities among a group of elite maize inbreeds as measured by pedigree, $F_{1}$ grain yield, heterosis, and RFLPs. Theor Appl Genet. 80:833-840.

Su J, Shen Q, Ho T, Wu, R (1998) Dehydration-stressregulated transgene expression in stably transformed rice plants. Plant Physiol. 117:913-922.

$\mathrm{Su}$ J, Wu R (2004) Stress inducible synthesis of proline in transgenic rice confers faster growth under stress conditions than that with constitutive synthesis. Plant Sci. 166: 941-948.

Vendruscolo ECG (2005) Transformação de trigo (Triticum aestivum L.) com o gene $p 5 c s$ e a avaliação de plantas transgênicas para tolerância ao estresse hídrico e baixas temperaturas. Maringá: Universidade Estadual de Maringá, Thesis (Doctor science)

Yamaguchi-Shinozaki K, Shinozaki K (2005) Organization of cis acting regulatory elements in osmotic and cold stress responsive promoters. Trends Plant Sci. 10:88-94.

Zadocks JC, Chang TT, Konzak CF (1974) A decimal code for growth stages of cereals. Weed Res. 14: 415-421.

Zhang CS, Lu Q, Verma DPS (1995) Removal of feedback inhibition of $\Delta^{1}$-pyrroline-5-carboxylate synthetase a bifunctional enzyme catalyzing the first two steps of proline biosynthesis in plants. J Biol Chem. 270:2049120496.

Zhu B, Su J, Chang M, Verma DPS, Fan YL, Wu, R (1998) Overexpression of $\Delta^{1}$-pyrroline-5-carboxylate synthetase gene and analysis of tolerance to water and salt-stress in transgenic rice. Plant Sci. 139:41-48. 